\title{
Joint associations of physical activity and screen time with overweight among japanese adults
}

Yung Liao ${ }^{{ }^{*}}$, Kazuhiro Harada ${ }^{2,3}$, Ai Shibata ${ }^{3}$, Kaori Ishii ${ }^{3}$, Koichiro Oka $^{3}$, Yoshio Nakamura ${ }^{3}$, Takemi Sugiyama ${ }^{4}$, Shigeru Inoue ${ }^{5}$ and Teruichi Shimomitsu ${ }^{5}$

\begin{abstract}
Background: Although both insufficient physical activity (PA) and high screen time (ST) are independent risk factors for obesity, how the combination of sufficient/insufficient PA and high/low ST could increase obesity risk among the adult population of Japan is not known. This study examined joint associations of PA and ST with overweight among Japanese adults.
\end{abstract}

Methods: An Internet-based survey collected data on height, weight, self-reported time spent in PA and ST, and sociodemographic variables from 2832 adults. Respondents were categorized into sufficient PA/low ST, sufficient PA/high ST, insufficient PA/low ST, or insufficient PA/high ST categories as per public PA guidelines and the median of ST. Logistic regression analysis examined the odds ratios (OR) of being overweight (body mass index, $\geq$ $25 \mathrm{~kg} / \mathrm{m}^{2}$ ) according to the categories of PA and ST.

Results: In comparison with the sufficient PA/low ST category, participants in the insufficient PA/high ST category were significantly more likely overweight $(\mathrm{OR}, 1.48 ; 95 \%$ confidence interval $[95 \% \mathrm{Cl}), 1.14,1.93)$ after adjusting for sociodemographic variables. A significantly higher OR for overweight (including obesity) among insufficient PA/ high ST category was also observed in men, but no significant association was found in women.

Conclusions: Both insufficient PA and prolonged ST contribute to overweight and obesity among Japanese adults. Public health initiatives addressing obesity in Japan need to consider both promoting PA and reducing ST, especially in men.

\section{Background}

Overweight and obesity increase the risk of developing chronic diseases including cardiovascular disease, hypertension, type 2 diabetes, and certain types of cancer $[1,2]$. Physically inactive lifestyles are considered to play important roles in the current obesity epidemic [3]. Research has consistently shown that physical activity (PA) is inversely associated with obesity measures $[4,5]$. Time spent in sitting (sedentary behavior) is also known to be associated with increased risk of obesity, independent of participation in PA [6,7].

Drawing on these research findings, an Australian study has examined the joint association of PA and sedentary behavior with obesity [8]. The study found that those who met PA guideline recommendations but

\footnotetext{
* Correspondence: anthroliao@fuji.waseda.jp

'Graduate School of Sport Sciences, Waseda University, Nakamura Laboratory

2-579-15 Mikajima Tokorozawa, Saitama 359-1192, Japan

Full list of author information is available at the end of the article
}

reported prolonged sedentary time and those with insufficient PA and lower sedentary time had similarly higher likelihood of being overweight compared with those who conducted sufficient PA and were low in sedentary time [8]. However, the combined effect of PA and sedentary behavior on obesity is not known in other countries. Japan offers a unique research opportunity in this context. Although the prevalence of obesity is relatively low in Japan compared with Western countries, it is increasing steadily [9]. In addition, partly because of easily available media-related technologies, television/ video viewing and Internet use are highly prevalent and increasing among adults [10]. Since computer and Internet use has been found associated with adult overweight and obesity [11], it is of interest to examine the health impact of screen-based sedentary behavior in the presence (and absence) of PA. This study examined the joint associations of PA and screen-based sedentary behavior with overweight among Japanese adults.
Ciomed Central 


\section{Methods}

\section{Participants}

Data for this study came from an Internet-based crosssectional survey in 2009. A total of 9418 adults were randomly selected from the database of a Japanese research service company (with approximately 264,000 registrants) and received invitation e-mails. Of these, 3000 individuals responded to the survey. Detailed methods and procedures have been reported elsewhere [12]. This study received prior approval from the Ethics Committee of Waseda University.

\section{Outcome variable}

The outcome variable of this study was body mass index (BMI) calculated from self-reported height and weight dichotomized into normal weight $\left(<25 \mathrm{~kg} / \mathrm{m}^{2}\right)$ or overweight (including obese, $\geq 25 \mathrm{~kg} / \mathrm{m}^{2}$ ), according to the criterion of Japanese National Health and Nutrition Survey [13].

\section{Exposure variable}

Exposure variable was calculated from levels of PA and screen time (ST). For PA the Short Version of International Physical Activity Questionnaire (IPAQ-SV) was used. Total time spent in vigorous-intensity PA, moderate-intensity $\mathrm{PA}$, and walking was calculated and dichotomized into "sufficient PA" ( $\geq 150$ minutes/week) or "insufficient PA" (< 150 minutes/week) based on public health guidelines [14]. Test-retest reliability and criterion validity of the Japanese version of IPAQ-SV have been validated [15]. For ST, participants reported their time spent in the following screen-related sedentary behaviors: watching television, videos, and DVDs; Internet use (except work related); and video game use. Reasonable validity and reliability were reported [16]. The sum of the time spent in these behaviors was dichotomized into "low ST" or "high ST" using the median (21 hours/week). According to the levels of PA and ST, participants were classified into the following four categories: sufficient PA/low ST; sufficient PA/high ST; insufficient PA/low ST; and insufficient PA/high ST.

\section{Sociodemographic variables}

Data on participants' sex, age (30-39; 40-49; 50-59 years), marital status (married; unmarried), educational level (junior high and high school degree; two-year college degree or equivalent; four-year college or higher degree), job status (full-time job; not full-time job), and household income (less than 5 million yen; 5-10 million yen; more than 10 million yen) were obtained from the research company.

\section{Data analysis}

Data for 2832 adults who provided complete information for the study variables were analyzed. Logistic regression was conducted to estimate the odds ratios (ORs) of being overweight by PA/ST categories adjusted for sociodemographic variables. The sufficient PA/low ST category was the reference for this analysis. Regression analyses were performed for the whole sample, and separately for men and women, based on the gender differences have previously been found [8]. Analysis was conducted using SPSS 15.0; the level of significance was set at $p<0.05$.

\section{Results}

Table 1 shows the sociodemographic characteristics of the total sample and the four PA/ST categories. Overall, $50 \%$ of the respondents were men and $74.5 \%$ were married. Of the total respondents, $33.6 \%$ were aged 30-39 years, $33.3 \%$ were aged $40-49$ years, and $33.1 \%$ were aged $50-59$ years. In addition, $47.6 \%$ of the participants had graduated from college or graduate school and $62.0 \%$ had full-time job, as well as $46.5 \%$ had $5-10$ million yen income. The proportion of overweight and obese participants was $21.8 \%$ for the total sample. Correlation coefficient between PA and ST was -0.17 , suggesting that these two behaviors were essentially independent from each other.

Table 2 shows ORs for being overweight or obese by combined categories of PA and ST for the total sample, for men, and for women, adjusting for sociodemographic factors. In the total sample, adults who were insufficient in PA and high in ST were 1.48 times more likely overweight compared with those who engaged in sufficient PA and were low in ST. The other categories (sufficient PA/high ST, insufficient PA/low ST) were not significantly different from the reference category. A similar pattern was observed in men. Compared with the reference category, men who engaged in insufficient PA and high ST were significantly more likely overweight. However, no significant association was found between the PA/ST categories and overweight in women.

\section{Discussion}

Japanese adults who engaged in insufficient PA and high ST were about 1.5 times more likely overweight than those with sufficient PA and low ST. Given that insufficient PA or high ST alone was not significantly associated with overweight, our findings suggest that it is the combination of lack of PA and prolonged ST that increases the risk of overweight and obesity in this sample of Japanese adults. This finding on the combined effect of PA and ST on overweight is consistent with a previous study that examined the joint association in the same manner [8]. However, our findings are different from that study in that we found the OR of being overweight was not significantly higher for sufficient PA/high ST and insufficient 
Table 1 Sample characteristics by Physical Activity (PA) and Sitting Time (ST) Categories

\begin{tabular}{|c|c|c|c|c|c|c|}
\hline & \multirow[b]{2}{*}{ Total } & \multicolumn{4}{|c|}{ Combined Categories of PA and ST } & \multirow[b]{2}{*}{$p$-value } \\
\hline & & $\begin{array}{l}\text { Sufficient PA/Low } \\
\text { ST }\end{array}$ & $\begin{array}{l}\text { Sufficient PA/High } \\
\text { ST }\end{array}$ & $\begin{array}{l}\text { Insufficient PA/Low } \\
\text { ST }\end{array}$ & $\begin{array}{l}\text { Insufficient PA/High } \\
\text { ST }\end{array}$ & \\
\hline No. (\%) & 2832 & $905(32 \%)$ & $656(23 \%)$ & $702(25 \%)$ & $569(20 \%)$ & - \\
\hline Sex & & & & & & $<0.001$ \\
\hline Male & $50.0 \%$ & $57.5 \%$ & $44.7 \%$ & $50.7 \%$ & $43.4 \%$ & \\
\hline Female & $50.0 \%$ & $42.5 \%$ & $55.3 \%$ & $49.3 \%$ & $56.6 \%$ & \\
\hline Age group & & & & & & $<0.001$ \\
\hline $30-39$ years & $33.6 \%$ & $35.6 \%$ & $27.7 \%$ & $38.0 \%$ & $31.6 \%$ & \\
\hline $40-49$ years & $33.3 \%$ & $29.8 \%$ & $34.3 \%$ & $36.8 \%$ & $33.4 \%$ & \\
\hline $50-59$ years & $33.1 \%$ & $34.6 \%$ & $38.0 \%$ & $25.2 \%$ & $35.0 \%$ & \\
\hline Marital status & & & & & & $<0.001$ \\
\hline Unmarried & $25.5 \%$ & $20.8 \%$ & $31.3 \%$ & $24.5 \%$ & $27.6 \%$ & \\
\hline Married & $74.5 \%$ & $79.2 \%$ & $68.8 \%$ & $75.5 \%$ & $72.4 \%$ & \\
\hline Educational level & & & & & & $<0.001$ \\
\hline Junior high/high school & $26.4 \%$ & $18.6 \%$ & $33.5 \%$ & $25.8 \%$ & $31.5 \%$ & \\
\hline Two-year college & $26.0 \%$ & $24.7 \%$ & $25.0 \%$ & $25.1 \%$ & $30.4 \%$ & \\
\hline $\begin{array}{l}\text { Four-year college/graduate } \\
\text { school }\end{array}$ & $47.6 \%$ & $56.7 \%$ & $41.5 \%$ & $49.1 \%$ & $38.1 \%$ & \\
\hline Job status & & & & & & $<0.001$ \\
\hline Full-time job & $62.0 \%$ & $68.3 \%$ & $53.7 \%$ & $69.8 \%$ & $52.2 \%$ & \\
\hline No full-time job & $38.0 \%$ & $31.7 \%$ & $46.3 \%$ & $30.2 \%$ & $47.8 \%$ & \\
\hline Household income (yen p.a) & & & & & & $<0.001$ \\
\hline$<5$ million & $38.0 \%$ & $31.3 \%$ & $41.6 \%$ & $36.9 \%$ & $45.9 \%$ & \\
\hline 5-10 million & $46.5 \%$ & $50.4 \%$ & $42.8 \%$ & $48.1 \%$ & $42.7 \%$ & \\
\hline$>10$ million & $15.5 \%$ & $18.3 \%$ & $15.6 \%$ & $15.0 \%$ & $11.4 \%$ & \\
\hline BMI & & & & & & 0.182 \\
\hline Normal weight & $78.2 \%$ & $79.4 \%$ & $79.1 \%$ & $78.3 \%$ & $74.9 \%$ & \\
\hline Overweight & $21.8 \%$ & $20.6 \%$ & $20.9 \%$ & $21.7 \%$ & $25.1 \%$ & \\
\hline Mean BMl, $\mathrm{kg} / \mathrm{m}^{2}(\mathrm{sd})$ & $\begin{array}{l}22.59 \\
(3.53)\end{array}$ & $22.46(3.25)$ & $22.51(3.49)$ & $22.52(3.50)$ & $22.99(4.02)$ & \\
\hline
\end{tabular}

Abbreviations: PA: physical activity; ST: screen time, p.a.: per annum.

PA/low ST categories. This is also inconsistent with previous studies that demonstrated associations of sedentary time with obesity measures independent of physical activity [6,7]. The inconsistency between this and previous studies may stem from behaviors that were not measured in this study such as nonscreen-based sedentary behaviors (e.g., during work and transport) and light-intensity physical activity. The latter has been shown associated with reduced metabolic risk independent of moderate-to-vigorous physical activity [17]. It is possible that those in the sufficient PA/high ST category may be low in nonscreen-based sedentary behaviors (they may afford high ST in their leisure time due to less time commitment for work or transport), and those in the insufficient PA/low ST category may be high in light-intensity activity (they may have to cut PA and ST to perform duties such as household chores). Our findings suggest potentially different behavioral

Table 2 Adjusted Odds Ratios of Overweight/Obese by Physical Activity (PA) and Sitting Time (ST) Categories

\begin{tabular}{|c|c|c|c|c|c|c|}
\hline & \multicolumn{6}{|c|}{ Being overweight (BMI, $\geq 25 \mathrm{~kg} / \mathrm{m}^{2}$ ) } \\
\hline & \multicolumn{2}{|c|}{ Total $(n=2832)$} & \multicolumn{2}{|l|}{ Men $(n=1416)$} & \multicolumn{2}{|c|}{ Women $(n=1416)$} \\
\hline & OR (95\% Cl) & $p$-value & OR $(95 \% \mathrm{Cl})$ & $p$-value & OR $(95 \% \mathrm{Cl})$ & $p$-value \\
\hline Sufficient PA/low ST & 1.00 (ref.) & - & 1.00 (ref.) & - & 1.00 (ref.) & - \\
\hline Sufficient PA/high ST & $1.13(0.87-1.46)$ & 0.37 & $1.30(0.94-1.79)$ & 0.11 & $0.87(0.55-1.40)$ & 0.57 \\
\hline Insufficient PA/low ST & $1.12(0.87-1.43)$ & 0.39 & $1.18(0.88-1.59)$ & 0.28 & $0.97(0.61-1.55)$ & 0.91 \\
\hline Insufficient PA/high ST & $1.48(1.14-1.93)$ & 0.003 & 1.50 (1.08-2.09) & 0.02 & $1.43(0.92-2.23)$ & 0.11 \\
\hline
\end{tabular}

OR adjusted for sex (whole sample), age, marital status, educational level, job status, and household income. 
mechanisms linking physical activity and sedentary behavior with metabolic risk between Japan and Western countries, where previous studies have been conducted. Further research using objective behavioral measures is warranted to explore such differences.

In this study, significant associations between combined PA/ST categories and likelihood of being overweight or obese were found in men but not in women. This pattern of sex difference diverges from the findings of studies conducted in Australia [18], Europe [19], and the United States [20], which have shown stronger associations between sedentary behavior and metabolic health risks in women. One possible explanation is that the prevalence of overweight or obesity is very low among women in this sample. It was $12.5 \%$, which is even lower than the national prevalence for women reported in the Japanese National Health and Nutrition Survey (20\%) [21]. It is possible that women in this sample, particularly those who are not very active, may pay close attention to diet so as to control their weight. Future studies should examine diet so as better to understand obesity risks among Japanese women.

Several limitations need to be considered. First, the study used a cross-sectional design; thus it is not possible to make causal inferences. Second, the utilization of IPAQ-SV may cause the overestimation of PA time due to recall bias [22,23]. Third, ST was not measured separately by weekday and weekend, which may contribute to an inaccurate estimation of ST. Fourth, as discussed above, potentially confounding behaviors such as lightintensity activity and diet were not assessed in the study. Finally, the study sample was extracted from the list held by an Internet survey company. Previous studies have indicated that respondents to Internet-based surveys are generally younger, better educated, have higher income and may have greater access to the Internet than respondents to traditional surveys [24,25]. Thus the findings obtained from our sample may not be representative for the entire adult population of Japan.

Regardless of the limitations, our findings suggest the importance of addressing both aspects of physical inactivity (insufficient PA and high ST) to reduce overweight and obesity at the population level. Future health promotion strategies addressing obesity in Japan should focus not only on increasing PA but also on reducing sedentary time, especially in men.

\footnotetext{
Acknowledgements

This study was supported by a Grant-in-Aid from the Ministry of Health, Labour, and Welfare of Japan (Comprehensive Research on Prevention of Cardiovascular Diseases and Other Lifestyle Related Diseases: H20Junkankitou-Ippan-001), Grant-in-Aid for Scientific Research (C) 20500604 from the Japan Ministry of Education, Culture, Sports, Science, and Technology, Grants-in-Aid for Scientific Research (No. 20800054) from the Japan Society for the Promotion of Science, and Global COE Program "Sport
}

Sciences for the Promotion of Active Life" from the Japan Ministry of Education, Culture, Sports, Science, and Technology.

\section{Author details}

'Graduate School of Sport Sciences, Waseda University, Nakamura Laboratory 2-579-15 Mikajima Tokorozawa, Saitama 359-1192, Japan. ªpan Society for the Promotion of Science, Sumitomo-Ichibancho Bldg., 6 Ichibancho,

Chiyoda-ku, Tokyo 102-8471, Japan. ${ }^{3}$ Faculty of Sport Sciences, Waseda University, 2-579-15 Mikajima Tokorozawa, Saitama 359-1192, Japan. ${ }^{4}$ Baker IDI Heart and Diabetes Institute, Level 4, 99 Commercial Road, Melbourne VIC 3004, Australia. ${ }^{5}$ Department of Preventive Medicine and Public Health, Tokyo Medical University, 6-1-1, Shinjuku-ku, Tokyo, 160-8402, Japan.

\section{Authors' contributions}

$Y L$ contributed to analysis and interpretation of data and drafted and revised the paper. $\mathrm{KH}$ participated in the study design, contributed to analysis and interpretation of data, and revised the paper. AS, KI, KO, SI conceived the study, participated in its design and coordination, and helped in drafting the manuscript. TSU, YN, TSH performed the sequence alignment and helped in drafting the manuscript. All the authors have read and approved the final manuscript.

\section{Competing interests}

The authors declare that they have no competing interests.

Received: 4 August 2011 Accepted: 30 November 2011

Published: 30 November 2011

\section{References}

1. Li Z, Bowerman S, Heber D: Health Ramifications of the Obesity Epidemic. Surg Clin North Am 2005, 85(4):681-701.

2. Visscher TL, Seidell JC: The public health impact of obesity. Annu Rev Public Health 2001, 22:355-75.

3. Kumanyika SK, Obarzanek E, Stettler N, Bell R, Field AE, Fortmann SP Franklin BA, Gillman MW, Lewis CE, Poston WC, Stevens J, Hong Y, American Heart Association Council on Epidemiology and Prevention, Interdisciplinary Committee for Prevention: Population-based prevention of obesity: The need for comprehensive promotion of healthful eating, physical activity, and energy balance. Circulation 2008, 118:428-464.

4. Dwyer T, Hosmer D, Hosmer T, Venn AJ, Blizzard CL, Granger RH, Cochrane JA, Blair SN, Shaw JE, Zimmet PZ, Dunstan D: The inverse relationship between number of steps per day and obesity in a population-based sample-the AusDiab study. Int J Obes 2007, 31:797-804.

5. Lindstrom M: Means of transportation to work and overweight and obesity: a population-based study in southern Sweden. Prev Med 2008, 46:22-28.

6. Healy GN, Wijndaele K, Dunstan DW, Shaw JE, Salmon J, Zimmet PZ, Owen N: Objectively measured sedentary time, physical activity, and metabolic risk: the Australian Diabetes, Obesity and Lifestyle Study (AusDiab). Diabetes Care 2008, 31:369-371.

7. Jakes RW, Day NE, Khaw KT, Luben R, Oakes S, Welch A, Bingham S, Wareham NJ: Television viewing and low participation in vigorous recreation are independently associated with obesity and markers of cardiovascular disease risk: EPIC-Norfolk population-based study. Eur J Clin Nutr 2003, 57:1089-1096.

8. Sugiyama T, Healy GN, Dunstan DW, Salmon J, Owen N: Joint associations of multiple leisure-time sedentary behaviours and physical activity with obesity in Australian adults. Int J Behav Nutr Phys Act 2008, 1(5):35.

9. McCurry J: Japan battles with obesity. Lancet 2007, 369(9560):451-2.

10. NHK: Survey on Time Use and Leisure Activities, Report from NHK. 2010.

11. Vandelanotte C, Sugiyama T, Gardiner P, Owen N: Associations of leisuretime Internet and computer use with overweight and obesity, physical activity and sedentary behaviors: cross-sectional study. J Med Internet Res 2009, 11(3):e28.

12. Liao Y, Harada K, Shibata A, Ishii K, Oka K, Nakamura Y, Inoue S, Shimomitsu T: Perceived Environmental Factors Associated with Physical Activity among Normal-Weight and Overweight Japanese Men. Int J Environ Res Public Health 2011, 8:931-943.

13. Ministry of Health, Labour and Welfare: National Health and Nutrition Survey in 2009 Ministry of Health, Labour and Welfare: Tokyo, Japan; 2009. 
14. Haskell WL, Lee IM, Pate RR, Powell KE, Blair SN, Franklin BA, Macera CA, Heath GW, Thompson PD, Bauman A: Physical activity and public health: updated recommendation for adults from the American College of Sports Medicine and the American Heart Association. Med Sci Sports Exerc 2007, 39(8):1423-1434.

15. Murase N, Katsumura T, Ueda C, Inoue S, Shimomitsu T: International standardization of physical activity level: reliability and validity study of the Japanese version of the International Physical Activity Questionnaire (IPAQ) (Kosei no Shihyo). J Health Welfare Statistics 2003, 49:1-9, (in Japanese).

16. Salmon J, Owen N, Crawford D, Bauman A, Sallis JF: Physical activity and sedentary behavior: a population-based study of barriers, enjoyment, and preference. Health Psychol 2003, 22(2):178-88.

17. Healy GN, Dunstan DW, Salmon J, Cerin E, Shaw JE, Zimmet PZ, Owen N: Objectively measured light-intensity physical activity is independently associated with 2-h plasma glucose. Diabetes Care 2007, 30(6):1384-9.

18. Healy GN, Dunstan DW, Salmon J, Shaw JE, Zimmet PZ, Owen N: Television time and continuous metabolic risk in physically active adults. Med Sci Sports Exerc 2008, 40(4):639-45.

19. Bertrais S, Beyeme-Ondoua JP, Czernichow S, Galan P, Hercberg S, Oppert JM: Sedentary behaviors, physical activity, and metabolic syndrome in middle-aged French subjects. Obes Res 2005, 13(5):936-44.

20. Ford ES, Kohl HW, Mokdad AH, Ajani UA: Sedentary behavior, physical activity, and the metabolic syndrome among U.S. adults. Obes Res 2005, 13(3):608-14.

21. Handbook of Health and Welfare Statistics 2009, Ministry of Health, Labour and Welfare. [http://www.mhlw.go.jp/english/database/db-hh/2-1. html], (accessed on 21 July 2011).

22. Hallal PC, Gomez LF, Parra DC, Lobelo F, Mosquera J, Florindo AA, Reis RS, Pratt M, Sarmiento OL: Lessons learned after 10 years of IPAQ use in Brazil and Colombia. J Phys Act Health 2010, 7(2):S259-64.

23. Rzewnicki R, Vanden Auweele Y, De Bourdeaudhuij l: Addressing overreporting on the International Physical Activity Questionnaire (IPAQ) telephone survey with a population sample. Public Health Nutr 2003, 6(3):299-305.

24. Shibata A, Oka K, Harada K, Nakamura Y, Muraoka I: Psychological, social, and environmental factors to meeting physical activity recommendations among Japanese adults. Int I Behav Nutr Phys Act 2009, 28(6):60.

25. Rhodes SD, Bowie DA, Hergenrather KC: Collecting behavioural data using the world wide web: considerations for researchers. J Epidemiol Community Health 2003, 57(1):68-73.

doi:10.1186/1479-5868-8-131

Cite this article as: Liao et al: Joint associations of physical activity and screen time with overweight among japanese adults. International Journal of Behavioral Nutrition and Physical Activity 2011 8:131.

\section{Submit your next manuscript to BioMed Central and take full advantage of:}

- Convenient online submission

- Thorough peer review

- No space constraints or color figure charges

- Immediate publication on acceptance

- Inclusion in PubMed, CAS, Scopus and Google Scholar

- Research which is freely available for redistribution

Submit your manuscript at www.biomedcentral.com/submit
Biomed Central 